\title{
Failure Analysis of Oil Tubes Containing Corrosion Defects Based on Finite Element Method
}

\author{
Xiaoben Liu ${ }^{1, *}$, Hong Zhang ${ }^{1,2, *}$, Meng Li $^{1}$, Qinquan Duan ${ }^{1}$, Yanfei Chen ${ }^{1}$ \\ ${ }^{1}$ College of Mechanical and Transportation Engineering, China University of Petroleum, Beijing, \\ 102249, China \\ ${ }^{2}$ China University of Petroleum(Beijing) Karamay Campus, Karamay, 834000, China \\ *E-mail: liuxiaoben1991@126.com; HZhang@cup.edu.cn
}

doi: $10.20964 / 2016.06 .27$

Received: 31 October 2015 / Accepted: 30 March 2016 / Published: 4 May 2016

\begin{abstract}
Oil tubes containing corrosion defects are vulnerable under complicated service load. In the oil field, corrosion of oil tubes is mainly electrochemical corrosion. In this study, failure analysis of the oil tube with two typical electrochemical corrosion defects, the grooving defect and the ellipsoidal pit, was conducted by finite element method. The complicated service load conditions were considered, and the effects of the defect dimensions on the strength of the tube were discussed in detail. Results show that, with the increase of the depth of the defect position in the tube for both defect types, the peak Mises stress decreases first and then increases. If the defect is in the shallow position of the tube, it is the axial tension that leads to the tensile fracture. But if the defect is in the deep position of the tube, it is the internal pressure that leads to the rupture. The depth of the defect has great influence on the tube strength, while the width and length of the defect have small influence on the tube strength, especially when the defect is in the shallow position of the tube. This study can be referenced for the failure analysis and strength evaluation of oil tubes with corrosion defects.
\end{abstract}

Keywords: N80 oil tube, electrochemical corrosion defects, complicated service load, finite element method, failure analysis

\section{FULL TEXT}

(C) 2016 The Authors. Published by ESG (www.electrochemsci.org). This article is an open access article distributed under the terms and conditions of the Creative Commons Attribution license (http://creativecommons.org/licenses/by/4.0/). 